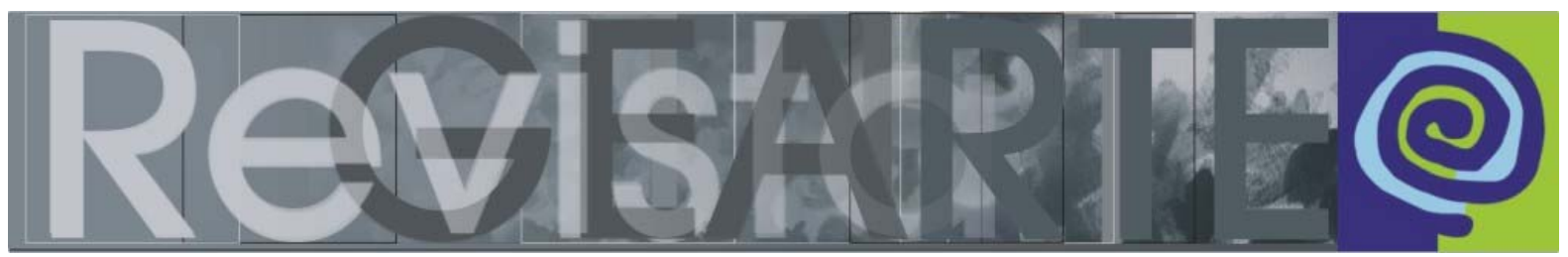

ISSN 2357-9854

\title{
Abordagem Triangular: leitura de imagens de diferentes códigos estéticos e culturais
}

\author{
Fernando Antônio Gonçalves de Azevedo (URFPE/UAG - Brasil) \\ Clarissa Martins de Araújo (UFPE/PPGE - Brasil)
}

\begin{abstract}
RESUMO
Partimos, neste texto, de uma compreensão da Abordagem Triangular como teoria de interpretação do universo das artes e culturas visuais filiada à teoria pós-colonialista. O texto está organizado em quatro tópicos articulados. No primeiro tópico, apresentamos a Abordagem Triangular como uma teoria aberta, não linear, que convida o arte/educador ao gesto de reelaborar. No segundo tópico, tratamos de argumentar sobre a filiação da Abordagem Triangular à teoria pós-colonial, ressaltando que a dimensão estética se interliga à dimensão cultural e que ambas são políticas. No terceiro tópico, tratamos de uma versão da história da Abordagem Triangular, pondo em destaque as transformações impulsionadas por tal teoria no campo da arte/educação nacional. Finalmente, no quarto tópico, à guisa de conclusão, argumentamos que a Abordagem Triangular provocou uma torção mais específica nas artes e culturas visuais e, também, no campo da arte/educação nacional, defendendo a descolonização e propondo a democratização da arte, seu ensino e sua história como direito de todos.
\end{abstract}

PALAVRAS-CHAVE

Abordagem Triangular. Dimensão Estética e Cultural. Teoria pós-colonial.

\section{ABSTRACT}

We start in this text, an understanding of the Triangular Approach as a theory of interpretation of the universe of arts and cultures visual affiliated to post-colonial theory. The text is organized in four articulated topics. In the first topic, we introduce the Triangular Approach as an open theory, non-linear, which invites the art/educator into the gesture of redesigning. The second topic, we argue about the affiliation of the Triangular Approach to the post-colonial theory, emphasizing that the aesthetic dimension interconnects to the cultural dimension and that both are political. In the third topic, we deal with a version of the history of the Triangular Approach, highlighting the changes driven by such a theory in the field of national art/education. Finally, in the fourth topic, by way of conclusion, we argue that the Triangular Approach caused a more specific twist in the arts and visual cultures and, in the broader field of national art/education, defending the decolonization, proposing the democratization of art, its teaching and its history as a right for everyone.

\section{KEY WORDS}

Triangular Approach. Aesthetic and Cultural dimension. Post-colonial theory.

\author{
Aqueles que nunca souberam domar \\ nem o vapor nem a eletricidade \\ Aqueles que não exploraram \\ nem os mares nem os céus \\ mas conhecem o país do sofrimento \\ nos seus mais insignificantes recantos \\ Aqueles cujas únicas viagens \\ foram de desenraizamento
}


Aqueles que foram amaciados pelas genuflexões

Aqueles que foram domesticados e cristianizados

Aqueles em quem inocularam a frouxidão (Aimé Césaire)

\section{Primeiros dizeres}

A teoria de que trataremos neste texto vem, ao longo de sua história, sendo renomeada: Metodologia Triangular, Proposta Triangular e Abordagem Triangular do Ensino das Artes e Culturais Visuais. Aqui vamos nomeá-la, simplesmente, de Abordagem Triangular.

Sua criadora - Ana Mae Barbosa (2009, p. XXX, grifos da autora) costuma enfatizar: "[...] não afirmo que a Proposta Triangular foi criada por mim. Prefiro usar o termo sistematizada, pois estava implícito na condição pósmoderna". Além disso, também esclarece que o marco inicial da Abordagem Triangular foi o Festival de Inverno de Campos de Jordão, edição de 1983.

Afirmamos nossa compreensão da Abordagem Triangular como teoria de interpretação do universo das artes e culturas visuais, a partir das palavras de Jorge Larrosa (2011, p. 35): “[...] 'teoria', [...] entendemos um gênero de pensamento e de escrita que pretende questionar e reorientar as formas dominantes de pensar e de escrever em um campo determinado."

Por ser profundamente dialógica, a Abordagem Triangular é uma teoria aberta, já que um de seus principais atributos é ser uma teoria viva, não linear, não acabada e, portanto, fecunda. Ela possibilita ao arte/educador questionar e reorientar o seu trabalho, compreende-o como sujeito da história capaz de reelaborar sua práxis (articulação entre teoria e prática) como um recriador e não como mero reprodutor.

No próximo tópico, nos dedicaremos a interligar a Abordagem Triangular à teoria pós-colonialista. 


\title{
Abordagem Triangular e sua filiação à teoria pós-colonial
}

Argumentar sobre a filiação da Abordagem Triangular à teoria pós-colonial não é difícil, porque sua autora, Barbosa, em diversas passagens de sua teoria declara tal filiação. Tomamos essa decisão considerando que um dos principais desafios das artes e culturas visuais na contemporaneidade refere-se à leitura da imagem, o que inevitavelmente nos encaminha para o reconhecimento da diversidade de códigos estéticos e culturais. Além do mais, partimos da ideia de que toda experiência estética ocorre de um determinado ponto de vista histórico, social e, por isso, é uma experiência também cultural. Essa perspectiva identifica-se com os Estudos Culturais que, de acordo com Tomaz Tadeu da Silva (2007, p. 134): "[...] estão preocupados com as questões que se situam na conexão entre cultura, significação, identidade e poder".

Bastante aproximada à compreensão de Silva, citada acima, em Tópicos Utópicos ${ }^{1}$ Barbosa (1998, p. 91, grifo da autora), problematiza:

\begin{abstract}
Uma criança negra que visite um museu que exiba arte ou "artefato" africano poderá de lá sair com seu ego cultural reforçado pelo conhecimento, apreciação e identificação com os valores vivenciais e estéticos da Arte Africana, ou completamente despossuído culturalmente e desidentificado com a gênese de sua cultura, dependendo da orientação que o profissional do museu que a recebe der à sua visita.
\end{abstract}

O diálogo entre os dois autores contribui para a nossa argumentação: no processo de produzir leituras de imagens, a dimensão estética e a dimensão política não podem ser dissociadas, uma vez que a separação entre as duas dimensões justifica ideologicamente as desigualdades sociais, fazendo prevalecer o código do poder.

1 A obra Tópicos Utópicos é marca da filiação da Abordagem Triangular à teoria pós-colonial. Nela Barbosa apresenta, do nosso ponto de vista, a primeira revisão da Abordagem Triangular — de Metodologia Triangular para Proposta — além de se posicionar politicamente em favor da diversidade de códigos estéticos e culturais diversos. Não é por acaso que se encontra nesse livro o texto Arte-educação pós-colonialista no Brasil: aprendizagem triangular (texto inicialmente escrito para ser apresentado no Congresso da InSEA - International Society for Education through Art - em 1994, ocorrido em Lisboa, portanto, na terra do colonizador). 
É muito importante dizer que as ações — ler/contextualizar/fazer - que constituem a Abordagem Triangular são articuladas e que a contextualização exerce um papel muito significativo na produção de sentidos do universo de imagens, quer sejam elas obras de arte, quer sejam elas cultura visual. A contextualização ao interligar o gesto de ler ao gesto de fazer torna significativa a experiência estética; passamos a dizer algo sobre a imagem que tem sentido para nós.

Como sugere o problema colocado por Barbosa sobre a criança negra, a contextualização, por se relacionar às ideologias, pode afastar e pode também aproximar o leitor. Isso acontece pela via das relações interculturais, ou seja, considera o leitor a partir de seus diferentes códigos estéticos e culturais. Aqui, precisamente, não podemos esquecer uma ideia de Michael Foucault (1996, p. 8-9):

[...] suponho que em toda sociedade a produção do discurso é ao mesmo tempo controlada, selecionada, organizada e redistribuída por certo número de procedimentos que têm por função conjurar seus poderes e perigos, dominar seu acontecimento aleatório, esquivar sua pesada e terrível materialidade.

A suposição de Foucault (1996) pode ser posta em diálogo com o problema apresentado por Barbosa (1998), pois, em nossa sociedade, a arte é pensada como um privilégio de poucos escolhidos.

Para enfrentar as questões advindas do pensamento de Barbosa e de Foucault, recorremos à ótica pós-colonialista e, por isso, tomamos como ancoragem, para nosso posicionamento, as palavras de Silva (2007, p. 126): "Para a teoria pós-colonial, não se pode separar a análise estética de uma análise das relações de poder. A estética corporifica, sempre, alguma forma de poder. Não há poética que não seja, ao mesmo tempo, também uma política". Assim, o que diz Silva anteriormente dialoga com o que diz o poeta Aimé Césaire, na epígrafe, de maneira poética e política ao mesmo tempo, sobre a história da escravidão das populações negras no mundo. Contextualizando a colonização em nosso país, Barbosa, (1998, p. 30) nos impacta dizendo: 
Fanon para nos analisar, pois só alguém como ele, psiquiatra, antropólogo e anticolonialista, daria conta de nossa conturbada personalidade colonizada.

Frantz Fanon nasceu na Martinica em 1925 e estudou psiquiatria e filosofia na França. Sua teoria foi profundamente marcada pela crítica às instituições coloniais e racistas. Sua vida de luta contra a história da colonização expressa em sua obra deixou fortes sinais no pensamento de Paulo Freire. Pedagogia do oprimido (2005) é um significativo exemplo da influência benfazeja do pensamento de Fanon sobre o pensamento de Freire. O último deixou como herança filosófica e política marcas no pensamento de Barbosa, já que a arte/educadora sempre ressaltou sua filiação ao pensamento freireano. Conforme Silva (2007, p. 126), "Os livros de Fanon, [...] Pele negra, máscaras brancas, publicado em 1952, e Os danados da terra, publicado em 1961, são considerados como precursores particularmente importantes da atual teoria póscolonial". Para Fanon (2008, p. 90): "A inferiorização é o correlato nativo da superiorização europeia. Precisamos ter coragem de dizer: é o racismo que cria o inferiorizado." A partir dessa lógica, é possível pensar: é o colonizador que inventa o colonizado.

Significa, pois, dizer que considerar as diferenças culturais é também considerar as diferentes estéticas. Por isso, é importante trazer para o âmbito da leitura da imagem a problematização da matriz estético/artístico/cultural colonial brasileira, buscando colocar sob suspeita os códigos do poder, ou como diz Silva (2011, p. 258), questionar a razão eurocêntrica "[...] masculina, branca, burguesa, setecentista e, portanto, particular, local, histórica." Tal razão estabelece os códigos do poder e apaga os códigos (estéticos e culturais) daqueles tidos como sem vez e voz.

A matriz estético/artístico/cultural colonial brasileira é pensada por Barbosa (1998, p. 30) como impositiva. No trecho a seguir, a autora aponta uma postura em favor da descolonização com os lembretes:

[...] pós-críticos que, se postos em prática, desmentiriam muitos dos preconceitos culturais, como, por exemplo, a ideia de que a melhor arte é a produzida pelos europeus e a de que pintura a óleo e a escultura em mármore são as mais importantes formas de arte. Essas ideias só reforçam o código hegemônico. Outra ideia preconceituosa de que a 
melhor arte tem sido produzida por homens, também seria desmitificada se a contextualizássemos em relação ao papel secundário que as sociedades têm determinado para as mulheres. A diferença hierárquica entre artesanato e arte, que é também preconceituosa, seria contestada se analisássemos o valor dos saberes dos pobres e dos ricos auferido pela cultura dominante.

A ideia de Barbosa pode ser justaposta à análise que Marilena Chaui (2006, p. 90) faz do que ela nomeia como matriz colonial brasileira. Observemos a seguir:

[...] estruturada pela matriz senhorial da Colônia, disso decorre a maneira exemplar em que faz operar o princípio liberal da igualdade formal dos indivíduos perante a lei, pois no liberalismo vigora a ideia de que alguns são mais iguais do que outros. As divisões sociais são naturalizadas em desigualdades postas como inferioridade natural (no caso das mulheres, dos trabalhadores, negros, índios, imigrantes, migrantes e idosos), e as diferenças também naturalizadas tendem a aparecer ora como desvios da norma (no caso das diferenças étnicas e de gênero), ora como perversão ou monstruosidade (no caso dos homossexuais, por exemplo). Essa naturalização, que esvazia a gênese histórica da desigualdade e da diferença, permite a naturalização de todas as formas visíveis e invisíveis de violência, pois, estas não são percebidas como tais [...].

Defendemos que a filiação da Abordagem Triangular à teoria pós-colonial é extremamente relevante, principalmente porque sendo uma teoria brasileira, contextualiza politicamente a sociedade brasileira e suas desigualdades herdadas de nosso processo colonizador.

Nossa argumentação, assim, buscou ressaltar que a interação entre a dimensão estética e a dimensão política na Abordagem Triangular é uma maneira de filiar-se à teoria pós-colonialista. Na direção das palavras de Silva (2007, p. 130): "Uma perspectiva pós-colonial [...] não separa questões de conhecimento, cultura e estética de questões de poder, política e interpretação". Evidencia-se, assim, a perspectiva descolonizada de ensino e de aprendizagem em artes e culturas visuais proposta pela Abordagem Triangular.

Uma versão da história da Abordagem Triangular será o tema do próximo tópico. 


\section{Uma versão da história da Abordagem Triangular}

A Abordagem Triangular foi sistematizada no âmbito da leitura do acervo do Museu de Arte Contemporânea da Universidade de São Paulo (MAC/USP) e aos poucos foi contaminando, positivamente, a escola. Fato que exige contextualizar historicamente esse momento da educação e da arte/educação paulistana. Paulo Freire era o Secretário de Educação da cidade de São Paulo e Ana Mae Barbosa era Diretora do MAC/USP. Foi nesse contexto que a referida abordagem começou a ser experimentada com grande ênfase na articulação entre a teoria e a prática, no processo de ensino, aprendizagem e pesquisa, tendo como atores principais os estudantes e arte/educadores do município de São Paulo. Interpretamos que trabalhar com os estudantes da escola pública da capital paulista foi uma escolha política, identificada ao processo de descolonização, pois o MAC/USP abriu suas portas, expondo seu acervo àqueles tidos como sem vez e sem voz.

Do nosso ponto de vista, a Abordagem Triangular surgiu na contramão das práticas arte/educativas marcadas pelo fazer livre-expressivo, centradas na expressão de sentimentos; em uma compreensão do papel do arte/educador como o cenógrafo das festas cívicas/escolares; pela formação do arte/educador numa ótica polivalente - por trabalhar teatro, dança, música e artes plásticas ao mesmo tempo.

Ressaltamos, nesse sentido, que a arte passou a ser obrigatória nas então escolas de $1^{\circ}$ e $2^{\circ}$ graus, em nosso país, não como resultado de uma exigência de educadores e arte/educadores, muito menos da sociedade brasileira. Conforme Barbosa (1991, p. 9):

\footnotetext{
Isto não foi uma conquista de arte-educadores brasileiros, mas uma criação ideológica de educadores norte-americanos que, sob um acordo oficial (Acordo MEC-USAID), reformulou a educação brasileira, estabelecendo em 1971 os objetivos e o currículo configurado na Lei Federal $n^{\circ} 5.692$ de Diretrizes e Bases da Educação.
}

Estávamos, pois, em um momento da arte/educação nacional, no qual a teoria era frágil, porque a grande ênfase concentrava-se no fazer, na ideia da livre-expressão. Predominava a formação polivalente do arte/educador, que, em 
geral, aprendia técnicas a serem utilizadas nas diferentes linguagens nos cursos de formação em Educação Artística.

Cabe aqui uma diferenciação, a partir do que afirma Barbosa (1991) sobre a ideia de livre-expressão. Segundo a autora, a livre-expressão se originou no Expressionismo, difundindo a compreensão de que a arte, no processo de educação, leva o estudante a expressar seus sentimentos e, por isso, a arte não é ensinada e sim expressada. Podemos dizer que a interpretação de Barbosa valia para as escolinhas filiadas ao Movimento Escolinhas de Arte (MEA), dos anos de 1940 a 1970, pois o processo arte/educativo nesse movimento tomava como aporte teórico o pensamento de Herbert Read, pensador inglês, autor de A Educação pela Arte (2001). Foi base teórica também para o MEA a obra Desenvolvimento da Capacidade Criadora (1961), de Viktor Lowenfeld e Lambert Brittain. Enquanto isso, na escola pública, a partir da Lei $n^{\circ}$ 5.692/71, tudo o que era realizado fazia menção à livre-expressão e tínhamos, então, técnicas artísticas desvinculadas do universo da arte e suas linguagens. No MEA, portanto, havia uma fundamentação teórica para o que se fazia em arte/educação, ao contrário do que ocorria na escola pública.

Naquele momento, havia também, no discurso dos arte/educadores, uma ênfase na ideia de criatividade, porém como espontaneidade. A esse respeito, Barbosa (1991, p. 11) afirma:

\begin{abstract}
A identificação da criatividade com a espontaneidade não é surpreendente porque é uma compreensão de senso comum. Os professores de arte não têm tido a oportunidade de estudar as teorias da criatividade ou disciplinas similares nas universidades porque estas não são disciplinas determinadas pelo currículo mínimo, logo só lhes resta o senso comum. Nas universidades que estendem o currículo além do mínimo, não encontrei (examinei onze currículos) nenhuma disciplina ligada ao estudo da criatividade, exceto na Universidade de São Paulo, onde um curso intitulado "Teoria da Criatividade" foi lecionado de 1977 a 1979 para alunos de artes nas áreas de cinema, música, artes plásticas e teatro.
\end{abstract}

Talvez, por isso, as primeiras palestras de Barbosa sobre os princípios da Abordagem Triangular e alguns experimentos significativos a partir dessa teoria em elaboração, especialmente quanto à leitura da imagem e à democratização da obra de arte, tenham provocado reações adversas nos arte/educadores 
vinculados aos slogans da época: "trabalhamos com o processo e não com o produto", "arte não se ensina porque é emoção, é sensibilidade".

Nesse contexto desfavorável, nasce o que hoje nomeamos de Abordagem Triangular, isto é, uma teoria de interpretação do universo das artes e culturas visuais que convida o arte/educador ao gesto de reelaborar, ou melhor, de exercer uma autonomia até então cassada, propondo a imagem como universo de ensino, aprendizagem e pesquisa.

É bom não esquecermos que o mesmo sistema que colocou a arte no currículo escolar (por meio da Lei $n^{\circ} 5.692 / 71$ ) era o que calava a voz dos artistas, acima de tudo, seu pensar crítico e libertário. A censura exercia o papel ideológico de reprimir o pensamento divergente. Não podemos esquecer as lições de Pierre Bourdieu (1974) sobre a economia das trocas simbólicas, pois, talvez, mais do que nunca a escola tenha sido o espaço privilegiado da reprodução da matriz estético/artístico/cultural de poder; isto é, o local onde as classes dirigentes da sociedade - aqueles que conforme Chaui (2006) exerciam o mando por serem superiores - aprendiam a dominar as classes populares os inferiores e esses, por serem inferiores, sem vez e sem voz, deveriam aprender a obedecer passivamente.

Eni Orlandi (2011), ao interpretar Bourdieu, diz que a escola é reprodutora e legitimadora das contradições sociais, por meio do discurso pedagógico, trazendo à tona o clima desfavorável em que Barbosa alça voos, com alguns filiados, na direção da constituição da Abordagem Triangular. Nas palavras de Orlandi, (2011, p. 22) ancorada em Bourdieu,

[...] a escola é a sede da reprodução cultural e o sistema de ensino é a solução mais dissimulada para o problema da transmissão de poder [...] a definição da escola em sua função de transmissão da informação acumulada (definição tradicional) dissocia sua função de reprodução cultural de sua função de reprodução social, aparecendo como colaboradora que harmoniza a transmissão de um patrimônio cultural que aparece como bem comum. No entanto, há uma correspondência entre a distribuição do capital cultural e do capital econômico e do poder entre as diferentes classes: a posse de bens culturais, e que uma formação social seleciona como dignos de serem possuídos, supõe a posse prévia de um código que permite decifrá-lo. 
O universo da arte, particularmente era tido como um capital cultural, posse (quase) exclusiva de uma elite guiada pelos códigos eurocêntricos. Qualquer tentativa de quebrar essa cadeia comparava-se à dessacralização de um universo decifrável apenas por meio de uma linguagem cuidadosamente hermética, para afastar qualquer profanador.

A Abordagem Triangular enfrentou o desafio de dessacralizar a arte como um bem e o museu como seu local de culto, defendendo que a experiência estética é direito de todos e opondo-se à concepção de arte/educação como um livre fazer desvinculado de teorias. Além do mais, também enfrentou os preconceitos e os pré-juízos instalados na sociedade e reproduzidos pela escola, como nos alerta Orlandi no fragmento acima. Barbosa (1998, p. 87) é categórica quanto a essa questão ao afirmar: "Preconceito de classe é ainda o grande inimigo do multiculturalismo no Terceiro Mundo. Tudo que é feito pelo pobre é artesanato e não arte; isso é o pensamento vigente."

A breve versão da história da Abordagem Triangular quer trazer à tona 0 grande desafio enfrentado por sua criadora e filiados, quer seja no campo da arte, quer seja no da arte/educação, ao questionar a distribuição desigual do capital cultural presente na sociedade, aponta a educação como processo de descolonização.

Arrematamos este tópico com mais um fragmento colhido do pensamento de Barbosa (1998, p. 80, grifos da autora), sobre uma questão, que não podemos esquecer:

Sabemos que a identidade cultural é construída em torno das evidências das "diferenças". Se as diferenças culturais são embaçadas, o "ego" cultural desaparece. Portanto, a procura por uma identidade cultural e a educação multicultural não são operações em diálogo, mas um inter-relacionamento complexo e dialético. Qualquer desequilíbrio reduzirá a educação multicultural a uma mera "cooptação das forças das minorias", que leva a uma educação neocolonizadora.

O compromisso do arte/educador é não abandonar o estado de luta constante, compreendendo que a dimensão estética e a dimensão política não podem ser dissociadas, se trabalhamos buscando o processo de descolonização. 
O processo de descolonização, marca da Abordagem Triangular, impulsiona a virada arte/educativa, tema do próximo tópico.

\section{A virada arte/educativa provoca uma torção}

Abrimos este tópico, já avisando que ele foi construído para apresentar, sucintamente, a virada arte/educativa, à guisa de conclusão do texto.

Sobre a virada arte/educativa é importante ressaltar que a ideia nasceu dos estudos sobre a virada linguística e a virada cultural, respectivamente ancorados em Paulo Ghiraldelli (2011) e em Peter Burke (2008). Essas viradas atribuem à linguagem um papel central, inclusive e, sobretudo, às linguagens artísticas na relação dos seres humanos com o mundo, o que significa dizer, em outras palavras, que isso ocorre porque nós humanos produzimos sentidos para o mundo por meio da palavra e da imagem.

Assim, a virada arte/educativa articula da virada linguística o direito que cada pessoa tem de dizer a sua palavra com a virada cultural - o direito a falar e agir no mundo a partir de sua cultura. Pensamos que, do ponto de vista brasileiro, o pensamento de Barbosa, especialmente a Abordagem Triangular, apresenta-se como uma interpretação importante para o campo do ensino e da aprendizagem das artes e culturas visuais, na medida em que a virada arte/educativa exige uma redefinição do que é cultura, em outras palavras, a virada arte/educativa nos leva a questionar a hegemonia de uma determinada cultura sobre as outras. Dessa forma, aprendemos com nossos colonizadores a não olharmos para nós como identidades culturais, por estarmos distantes do padrão cultural estabelecido por eles. Vem, em oposição ao colonialismo, o trabalho de Barbosa a partir da Abordagem Triangular no MAC/USP (BARBOSA, 1998, p. 80-81, grifo nosso):

Em 1991, durante a Bienal de São Paulo, uma organização norte-
americana, a International Arts, promoveu um seminário sobre Arte e
Multiculturalismo. Só os norte-americanos falaram sobre o tema. [...]
nem mesmo o organizador brasileiro foi capaz de reconhecer a política
multicultural do Museu de Arte Contemporânea [...], única instituição
no Brasil com tal preocupação naquele momento. [...] que tinha,
naquela oportunidade, uma exposição interdisciplinar e
intercultural sobre representações estéticas da mata nas artes e nas
ciências, incluindo artistas populares, eruditos e desenhistas 
científicos. Essa exposição, A Mata, fazia parte do projeto Estética das Massas, que teve lugar no museu de 1987-1993, contra o desejo dos historiadores tradicionais de arte e curadores da Universidade, mas muito bem aceito pelos antropólogos e muitos críticos de arte. Esse projeto [...] visava explorar outras relações menos sacrossantas entre museu e público, trazendo diferentes classes sociais ao museu.

O sentido de indignação, expresso no discurso de Barbosa, nos levou a evidenciar a arte/educadora e a cidadã como dimensões de sua identidade não dissociadas, pois o seu discurso não é apenas um protocolo profissional, mas o discurso de uma cidadã brasileira denunciando uma atitude colonizadora.

Pensamos que a estratégia de poder, nesse caso, não foi aleatória e, sim, uma espécie de demarcação de território. Era como se afirmassem: para ter acesso a arte é necessário ser versado nela, enquanto a política de descolonização desenvolvida no MAC/USP visava, por meio do acesso ao ensino e à aprendizagem da arte, a democratização desse bem. Assim, a virada arte/educativa começa a nascer no horizonte da arte/educação nacional.

Barbosa ainda enfatiza que o Programa Multiculturalista do MAC/USP buscava estabelecer relações mais dialogais entre o museu e o público, por meio do acesso de diferentes classes sociais (e suas estéticas) ao espaço. Fizeram parte do programa citado por Barbosa as seguintes exposições: Arte e Loucura (1987), Carnavalescos (1987), Civilidade da Selva, Mitos e Iconografia Indígena na Arte Contemporânea (1988), Conexus (1989), A Estética do Candomblé (1989), Latas e Sucatas: Arte Periférica (1989) e A Mata (1990).

Imaginemos, então, no contexto histórico, social e político ainda muito marcado pela censura ditatorial recente e pela história da colonização, falarmos de leitura da imagem por meio da democratização do museu (e da arte), cujo acervo está à disposição dos estudantes de escolas públicas e de seus professores. É nessa perspectiva que vemos a Abordagem Triangular operando, historicamente, como uma transformação paradigmática que nomeamos de virada arte/educativa.

A Abordagem Triangular ao desencadear a virada arte/educativa provoca historicamente uma espécie de torção no campo das artes e culturas visuais e 
no campo da arte/educação, ao deslocar o eixo do fazer para a elaboração, acrescentando a ideia de arte como expressão, a de arte como conhecimento histórico, social e cultural. Assim, a arte passa de mero objeto de contemplação, exigindo a produção de sentidos e transformando a postura do arte/educador de fazedor em um pesquisador de arte que visa, por meio da leitura da obra de arte e da cultura visual, a democratização desse conhecimento pelo processo arte/educativo. Ser arte/educador, no contexto da virada arte/educativa, caracteriza-se pela busca da leitura do discurso visual por meio de interpretações que articulam a dimensão estética com a dimensão política.

A virada arte/educativa, ao enfatizar a leitura da imagem (obra de arte e cultura visual), ressitua o processo de ensino e aprendizagem das visualidades, promovendo a seguinte passagem: da banalidade imposta pela ideia de um fazer artístico escolar, que era (ainda é?) completamente distante do universo das artes, pois a arte, compreendida como conhecimento não entrava na escola, à busca, hoje, de esforços na direção da ideia de arte como conhecimento histórico, social e cultural marcam o processo de leitura da imagem.

A ideia de virada arte/educativa parte, portanto, do princípio de que as obras de arte e a imagem são construções estéticas, históricas, sociais e culturais, reconfigurando o papel social e histórico do arte/educador e o da própria arte no contexto da educação. Essa virada requer do arte/educador a postura de não ser mais um mago das técnicas, um fazedor, como nos anos de 1970, mas propõe outros desafios. Entre eles, cabe ao arte/educador compreender-se como um propositor de situações, um problematizador da e na mediação entre a arte e o leitor, tendo como guia a seguinte ideia: a arte possibilita repensarmos nossas certezas e reinventarmos nosso cotidiano.

\section{Referências}

BARBOSA, Ana Mae. A imagem no ensino da arte: anos de 1980 e novos tempos. São Paulo: Perspectiva; Porto Alegre: Fundação IOCHPE, 1991.

BARBOSA, Ana Mae. A imagem no ensino da arte: anos de 1980 e novos tempos. São Paulo: Perspectiva, 2009.

BARBOSA, Ana Mae. Tópicos utópicos. Belo Horizonte: C/Arte, 1998.

BOURDIEU, Pierre. A economia das trocas simbólicas. São Paulo: Perspectiva, 1974. 
BURKE, Peter. O que é história cultural? Rio de Janeiro: Zahar, 2008.

CÉSAIRE, Aimé. Negritude. In: FANON, Frantz. Pele negra, máscaras brancas. Tradução de Renato da Silveira. Salvador: EDUFBA, 2008.

CHAUI, Marilena. Brasil: mito fundador e sociedade autoritária. São Paulo: Fundação Perseu Abramo, 2006.

FOUCAULT, Michel. A ordem do discurso. São Paulo: Edições Loyola, 1996.

FREIRE, Paulo. Pedagogia do oprimido. São Paulo: Paz e Terra, 2005.

GHIRALDELLI, Paulo. A aventura da filosofia: de Heidegger a Danto. Barueri, SP: Manole, 2011.

GHIRALDELLI, Paulo. A virada linguística. Disponível em:

<https://ghiraldelli.files.wordpress.com/2008/07/virada.pdf>. Acesso em: 01 maio 2011.

LARROSA, Jorge. Tecnologias do eu e educação. In: SILVA, Tomaz Tadeu da. (Org.). O sujeito da educação: estudos foucaultianos. Petrópolis: Vozes, 2011.

LOWENFELD, Viktor; BRITTAIN, W. Lambert. Desenvolvimento da capacidade criadora. Tradução de Álvaro Cabral. São Paulo: Mestre Jou, 1977.

ORLANDI, Eni. A linguagem e seu funcionamento: as formas do discurso. Campinas: Pontes, 2011.

READ, Herbert. Educação pela arte. São Paulo: Martins Fontes, 2001.

SILVA, Tomaz Tadeu da. O adeus às metalinguagens educacionais. In: SILVA, Tomaz Tadeu da. (Org.). O sujeito da educação: estudos foucaultianos. Petrópolis: Vozes, 2011.

SILVA, Tomaz Tadeu da. Documentos de identidade: uma introdução às teorias do currículo. Belo Horizonte: Autêntica, 2007.

\section{Fernando Antônio Gonçalves de Azevedo}

Doutor em Educação pela Universidade Federal de Pernambuco (UFPE), mestre em Artes pela Universidade de São Paulo (USP), especialista em Ensino da Arte pela Universidade Federal do Rio Grande do Norte (UFRN), especialista em Artes Cênicas pela UFPE e graduado em Filosofia pela Universidade Católica de Pernambuco (UNICAP). Professor do curso de Pedagogia na Unidade Acadêmica de Garanhuns da Universidade Federal Rural de Pernambuco (UFRPE/UAG). Participa do Grupo de Pesquisa em Educação e Arte - GEARTE, DGP/CNPq e do Grupo de Pesquisa Formação de Professores, Arte e Inclusão - GEFAI, DGP/CNPq.

E-mail: f_azevedo@hotmail.com

Currículo: http://lattes.cnpq.br/6665135954352936

\section{Clarissa Martins de Araújo}

Doutora em Sciences de L'education - Universite de Toulouse II (Le Mirail), mestre em Distúrbios da Comunicação pela Pontifícia Universidade Católica de São Paulo (PUCSP) e graduada em Fonoaudiologia pela Universidade Católica de Pernambuco (UNICAP). Atualmente é Professora Adjunta do Departamento de Psicologia e Orientação Educacionais e do Programa de PósGraduação em Educação, da Universidade Federal de Pernambuco. Pesquisadora do Núcleo de Formação de Professores e Prática Pedagógica, com ênfase em estudos sobre a Educação Inclusiva e Ensino de Artes. Está vinculada ao Grupo Formação de Professores e Profissionalização Docente, DGP/CNPq e ao Grupo de Pesquisa Formação de Professores, Arte e Inclusão -GEFAI, DGP/CNPq.

E-mail: clarissa.araujo@yahoo.com.br

Currículo: http://lattes.cnpq.br/2395569396317875 